\title{
Metodologia de problematização como processo avaliativo em um curso profissionalizante na área da saúde
}

\author{
Luís Felipe Pissaia \\ Enfermeiro, Mestrando em Ensino \\ Especialista em Gestão e Auditoria dos Serviços da Saúde \\ Universidade do Vale do Taquari - UNIVATES - Brasil \\ $\bowtie$ lpissaia@universo.univates.br \\ Marli Teresinha Quartieri \\ Doutora em Educação \\ Universidade do Vale do Taquari - UNIVATES - Brasil \\ Nélia Maria Pontes Amado \\ Doutora em Matemática \\ Universidade de Algarve - Portugal \\ Susana Paula Graça Carreira \\ Doutora em Educação \\ Universidade de Lisboa - Portugal \\ Márcia Jussara Hepp Rehfeldt \\ Doutora em Informática na Educação \\ Universidade do Vale do Taquari - UNIVATES - Brasil

\section{Arlete Eli Kunz da Costa} \\ Enfermeira, Doutora em Ambiente e Desenvolvimento \\ Universidade do Vale do Taquari - UNIVATES - Brasil
}

Recebido em 02 de setembro de 2017

Aceito em 07 de dezembro de 2017

\section{Resumo:}

Este estudo objetiva analisar a utilização da metodologia da problematização como processo avaliativo de estudantes na área da saúde. Utilizou-se como campo de estudo uma turma composta por cinco estudantes de um curso profissionalizante de cuidador de idosos. Os resultados observados versam sobre a dificuldade em incorporar a metodologia da problematização como um processo avaliativo em um currículo já estruturado. Verificou-se que os alunos ainda possuem um estigma quando indagados sobre avaliações, inferindo sobre situações punitivas. Observou-se que os estudantes compreenderam a importância do processo e utilizaram-se dele para exercitar sua própria aprendizagem. Considera-se que a metodologia utilizada possibilitou mensurar de modo subjetivo a aprendizagem dos estudantes, contemplando suas próprias discussões e conhecimentos prévios estabelecidos em sala de aula.

Palavras-chave: Avaliação, Ensino Profissionalizante, Problematização, Ensino em Saúde.

\section{Problematizing methodology as an evaluation process in a professional course in the health area}




\begin{abstract}
:
The purpose of this study is to analyze the use of the problematizing methodology as an evaluation process in the health area. The study field used comprised five students from am elderly care worker vocational course. The observed results describe the difficulty to incorporate the problematizing methodology as an evaluation process in an already structured curriculum. It was found that students still carry a stigma when inquired about evaluations and infer about punitive situations. It was observed that the students understand the importance of the process and made use of it while performing their own learning. It is considered that the methodology used allow to subjectively measure student learning by including their own discussions and previous knowledge established in the classroom.
\end{abstract}

Keywords: Evaluation, Vocational Teaching, Problematizing, Teaching in Health.

\title{
Metodología de problematización como proceso evaluativo en un curso profesional en el área de la salud
}

\section{Resumen:}

El objetivo de este estudio es analizar la utilización de la metodología de problematización como proceso evaluativo de estudiantes en el área de la salud. Se utilizó como campo de estudio un grupo compuesto por cinco estudiantes de un curso profesional de cuidador de ancianos. Los resultados observados tratan de la dificultad en incorporar la metodología de la problematización como proceso evaluativo en un currículo ya estructurado. Se verificó que los alumnos todavía presentan un estigma cuando preguntados sobre evaluaciones, infiriendo sobre situaciones punitivas. Se observó que los estudiantes comprendieron la importancia del proceso y se valieron de él para ejercitar su propio aprendizaje. Se considera que la metodología utilizada posibilitó medir de modo subjetivo el aprendizaje de los estudiantes, contemplando sus propias discusiones y conocimientos previos establecidos en sala de clase.

Palabras clave: Evaluación, Enseñanza Profesional, Problematización, Enseñanza en Salud

\section{INTRODUÇÃO}

Os modelos de ensino praticados na área da saúde sempre seguiram um limiar educacional baseado em adequações à sociedade contemporânea, e conforme Carneiro e colaboradores (2017), por vezes, perderam a integralidade ao especializar o conhecimento e, ao mesmo, passo a equidade tornou-se subjugada por métodos de avaliação não efetivos baseados em notas. E, conforme Santos (2016), atualmente, há uma demanda principalmente internacional, alavancada por pesquisadores norte-americanos, de qualificação e uniformidade do trabalho em saúde que busca uma relevância ética e moral à prática do ensino em saúde.

Nas últimas décadas, de acordo com Cunha et al. (2016), inúmeras reflexões seguiram os processos de mudança e conscientização sobre novos modelos de ensino, baseados principalmente na problematização de experiências e possibilidades de desenvolvimento e aperfeiçoamento das habilidades e competências necessárias aos futuros profissionais. Para 
tanto, uma das dificuldades encontradas no contexto de ensino em saúde é a necessidade de avaliar o aluno, já que as metodologias problematizadoras não são frequentemente utilizadas (RIBEIRO et al., 2016).

Tal afirmativa, de acordo com Costa e Cotta (2016) sustenta-se na individualidade de cada ser humano, que por sua vez, instiga a diferentes pensamentos, compreensões e atitudes perante determinada situação que afloram incessantemente em discussões baseadas nas dinâmicas de problematização sobre saúde. Por si só, a área das ciências da saúde diferencia-se das demais por representar modelos de intervenções e resoluções de problemas baseados nas compreensões do próprio indivíduo, ao passo que sua bagagem de conhecimento empírico e científico influencia diretamente na tomada de decisão (ZIMMERMANN et al., 2016).

Partindo desse pressuposto, os processos avaliativos possuem uma tendência a serem inovadores, conforme Polizeli e colaboradores (2017), não refletem teorias vigentes, pois as mesmas não conseguem incorporar um modelo de avaliação justo e integral ao estudante. Em consonância, Rocha, Warling e Toassi (2016) destacam que a partir disso, compunha-se, um cenário de intervenção criativa, abordando a necessidade de incorporação de modelos técnicos científicos e rupturas às tradicionais avaliações em saúde.

Esse texto assume caráter reflexivo, tendo como objetivo analisar a metodologia de problematização como processo avaliativo de estudantes na área da saúde. Tal reflexão justifica-se por meio da necessidade de qualificação da formação do profissional da saúde, levando em consideração as suas próprias compreensões e bagagem de conhecimento adquiridos durante a trajetória pessoal e profissional problematizadas em sala de aula. Estruturando assim uma avaliação em que o estudante participe ativamente do processo e o professor compreenda suas individualidades e potencialidades para a aprendizagem do conteúdo.

\section{FUNDAMENTAÇÃO TEÓRICA}

Os processos de avaliação da aprendizagem na área da saúde compreendem um paradigma relutante tradicional a ser sobreposto em sala de aula, os motivos sobressaem às 
técnicas de ensino utilizadas que, por vezes, não oferecem abertura para a realização da inovação na área. Contudo, o ensino em saúde torna-se um campo fértil de possibilidades para experimentarem-se novos métodos avaliativos.

Ainda assim a flexibilização dos modelos vigentes apresenta dificuldades, sendo que o estudante percebe a avaliação como uma demanda obrigatória, dialogando inclusive sobre espaços educacionais punitivos em que a aprendizagem não possui correlação com o processo avaliativo em saúde. Sendo assim, a seguir pretende-se fundamentar a avaliação na área da saúde e a metodologia de problematização, pois se acredita que ambas caminham juntas ao interligar o conhecimento com a realidade do estudante, gerando assim a aprendizagem esperada.

\section{PROCESSOS AVALIATIVOS DA APRENDIZAGEM EM SAÚDE}

No ambiente acadêmico contemporâneo acontecem diversas reflexões acerca dos processos avaliativos da aprendizagem. Fernandes (2014) destaca a responsabilidade na formação do futuro profissional condizente com as expectativas sociais. Partindo desse pressuposto, Batista e colaboradores (2017), reforçam que a avaliação constitui-se como algo presente e permanente no cotidiano do estudante, principalmente por estruturar-se como importante no contexto curricular obrigatório.

Para tanto, a avaliação possui uma significância sob a concepção de quem a realiza, estando sob julgamento aspectos não só conceituais sobre o conhecimento repassado em sala de aula, mas diferentes magnitudes culturais que se encontram enraizadas na formação histórica das escolas com bases tradicionais (SORDI e LUDKE, 2009). Já na área da saúde, conforme Carneiro et al. (2017) a avaliação passa a ser a garantia de uma formação profissional, de acordo com as características esperadas de um futuro profissional.

Neste sentido, Xavier et al. (2017) destaca que a avaliação em saúde espelha-se na construção de um meio reflexivo, possibilitando o envolvimento dos sujeitos no processo. Assim diversas perspectivas afloram perante a articulação da aprendizagem, tornando-os parte do segmento de inter-relação no ensino em saúde. Ao esmerar-se sobre concepções avaliativas apropriadas, surgiu a perspectiva de que, por meio da participação efetiva dos 
próprios estudantes em suas avaliações, a apropriação do conteúdo tornar-se-ia apropriada à formação, conforme Hartz (2017, p. 687), fundamenta no seguinte trecho:

\begin{abstract}
No entanto, a busca de solução das controvérsias inerentes a estas parcerias leva a inovações cuja emergência é facilitada pela pesquisa avaliativa que organiza espaços de reflexividade para o conjunto dos atores. Estas condições facilitam o dimensionamento e a institucionalização de soluções inovadoras que devem ser parte dos processos decisórios, contribuindo para que a avaliação seja um instrumento efetivamente utilizado para a redução das desigualdades sociais em saúde.
\end{abstract}

Sendo assim, os processos de avaliação podem ser verificados como inovadores e inerentes ao processo de formação social. As diferentes formas de avaliar-se, de acordo com Veloso, Abrantes e Craveiro (2011), possibilitam ao estudante da área saúde, um diferencial em sua aprendizagem. Diante deste contexto, passa-se então a discutir sobre a responsabilidade não só dele, mas do próprio professor neste cenário, que atua como um mediador da apropriação do conhecimento. Sob este questionamento, Alves, Faria e Costa (2017), comentam que um processo avaliativo em saúde finaliza-se com a apropriação do conhecimento por meio de sua aprendizagem. No entanto, o caminho de assimilação e maturação deve ser influenciado pela avaliação que permite uma reflexão sobre o caminho que está sendo trilhado.

Sob esta concepção, Sordi e Ludke (2009) predizem em seu estudo_que a avaliação recebe destaque por desempenhar uma estrutura de realimentação de conhecimento ao estudante, sustentando o segmento próprio das estruturas apreendidas em sala de aula, juntamente com as concepções próprias de cada indivíduo e que são desenvolvidas por meio de suas experiências. Ao assumir este formato, a avaliação não é mais vista como algo punitivo, divisório ou inflexível. E, segundo Carvalho e Meirelles (2017), apontam para um modelo de experiência formativa em saúde, onde o conhecimento não oferece respostas e sim portas para adentrar em novas reflexões. Nessa mesma perspectiva, Cunha et al. (2017) salientam que o conjunto de reflexões que o indivíduo realiza infere-se que suas próprias compreensões sobre o mundo que o rodeia influencie no processo de aprendizagem. 


\section{A PROBLEMATIZAÇÃo COMO PROCESSO AVALIATIVO EM SAÚDE}

Quando se esmera por um modelo de avaliação circunda-se em por moldes pragmáticos, que, conforme Sordi e Ludke (2009) são permeados por técnicas fragmentadas associadas ao conteúdo representando a simbologia de estar ou não apto para desenvolver determinada atividade. No entanto, Fernandes (2014), conclui que quando se pretende avaliar um estudante na área da saúde, o professor necessita de criatividade, pois a subjetividade impera nos processos particulares de apreensão das ideias essenciais.

A subjetividade guia as metodologias fomentadas em sala de aula, pois corresponde a um modelo inclusivo de diversidades de pensamento e capacidade de digerir determinada situação, e que, conforme Cunha et al. (2016), contribui para instrumentalizar uma ação resolutiva cabível. Por consequência, a avaliação subjetiva exige uma transparência interpessoal ímpar entre os sujeitos. Diretamente pode-se citar o professor e o estudante, mas que além destes, envolve os demais seres que constituem o meio social, bem como Coutinho e Dias (2017, p. 47), perfazem no seguinte excerto:

As problemáticas disparadas em torno de temas diversos, ligados direta ou indiretamente à produção de saúde, avultados pela arte, constituem-se, na dimensão dos compartilhamentos, como artefatos de diálogo, de implicações e, sobretudo, protagonismo entre os sujeitos [...].

Em consonância com Ribeiro et al. (2016), a ideia de metodologia de problematização relaciona-se diretamente a máxima de construção interpessoal de conceitos e compreensões por meio de discussões. Essas são realizadas preferencialmente em grupos de indivíduos com o intuito de representar pontos de vista diferente uns dos outros. Ainda para Veloso, Abrantes e Craveiro (2011), a potencialização deste processo ocorre através da desmistificação de certos preconceitos, neste caso a avaliação, bem como a realização do exercício de desapego a ideais pré-estabelecidos e aceitação de novos modos de construir a aprendizagem.

Neste sentido, conforme Costa e Cotta (2016), a problematização parte de um objeto inicial, que instiga e fomenta as atividades que serão desenvolvidas posteriormente, pois sempre há um problema a ser resolvido e, neste caso, sua resolução parte de cada estudante. Este pressuposto foi seguido durante o curso. Por este motivo, segundo Fernandes (2014), a 
problematização é utilizada com frequência na área da saúde, por representar uma relação à qual o estudante permeia um circuito de ideias que buscam solucionar o problema inicial.

Em suma espera-se que o estudante ciente de um contexto que represente um problema ou uma situação cotidiana e realize o exercício de tomada de decisão com base no conteúdo aprendido em sala de aula e nas próprias conjecturas criadas a partir de suas vivências no meio comunitário (RIBEIRO et al., 2016). Por este motivo que a avaliação da aprendizagem torna-se efetiva, pois, de acordo com Guerin et al. (2017), ela denota a integração subjetiva do próprio estudante no meio contextualizado, fazendo com que a problemática direcione suas compreensões e fixem o conteúdo por meio de experiências e simbologias construídas.

\section{METODOLOGIA}

Esta pesquisa pode ser considerada um estudo descritivo e exploratório, com abordagem qualitativa. Apresenta-se como campo de estudo, uma turma de cinco alunas de um curso profissionalizante da área da saúde, denominado de "Curso para cuidadores de idosos". Os encontros acontecem semanalmente, possuindo uma carga horária total de 55 horas. Tiveram início no mês de abril de 2017, com previsão de término para o mês de outubro do mesmo ano. A Instituição Profissionalizante localizada no interior do Rio Grande do Sul, Brasil, criou esse curso a partir de uma demanda profissional da região, a qual sentia a falta de qualificação na área de assistência aos idosos. Neste sentido, objetiva capacitar à mão de obra regional e qualificar a formação e atuação dos profissionais da área da saúde.

O curso aborda uma base curricular básica para a formação na área de assistência ao idoso, sendo composto por quatro módulos: $1^{\circ}$ Idoso e a Sociedade; $2^{\circ}$ Sistemas (Anatomia e Fisiologia Humana); $3^{\circ}$ Processo de saúde e doença no envelhecer e $4^{\circ}$ Intercorrências na terceira idade. Os processos avaliativos sempre estiveram presentes durante a construção curricular do curso, pois o colegiado composto pelos professores e coordenação pedagógica sempre esteve à frente de um processo contemporâneo e que pudesse garantir a aprendizagem dos alunos. Neste sentido, buscou-se nortear cada um dos quatro módulos 
com três atividades avaliativas cada, possuindo abertura para o professor definir os métodos empregados.

O módulo escolhido para aplicação do processo avaliativo foi o segundo, denominado "Sistemas", onde são trabalhados conteúdos referentes à Anatomia e Fisiologia Humana com enfoque para as mudanças no organismo de uma pessoa idosa. Este módulo, em especial, é o que possui maior carga horária sendo composto por vinte horas ministradas em cinco aulas.

O conteúdo básico do módulo compreendeu os sistemas humanos, como por exemplo, os sistemas musculoesquelético, cardiovascular, urinário, tegumentar, dentre outros que formam a base para a aprendizagem em anatomia e fisiologia humana. Neste sentido seguindo a tendência da proposta de problematização, foram sendo trabalhados textos de opinião sobre o assunto, além de um filme de curta duração que compuseram momentos entre a exposição dos conteúdos, conferindo um espaço rico de discussão e propulsão da ideia central proposta.

Os textos utilizados foram "A necessidade de qualidade de vida na terceira idade" que permeia sobre os processos de bem estar e saúde da população idosa, apoiando-se no regime de políticas públicas vigentes. O segundo texto utilizado foi, “Aborto afetivo" ${ }^{2}$ o qual trata das relações entre país e filhos, trazendo a tona um limiar paramétrico sobre as mudanças ocorridas nestas relações.

Já o último texto, "Novos velhos: o envelhecimento do século XXI"3 desafia a pensar sobre uma era, onde o idoso coloca-se a frente de seus próprios paradigmas sociais e culturais para legitimar sua importância enquanto agente social. Utilizou-se também de um filme de curta duração, "Holocausto Brasileiro", produzido pela HBO com direção da jornalista Daniela Arbex, que se constitui como um documentário/memória do Hospital Colônia de Barbacena, estado de Minas Gerais, Brasil, onde houve o que se chama atualmente de genocídio de por volta de 60 mil indivíduos. Trabalharam-se estes materiais

\footnotetext{
${ }^{1}$ PISSAIA, Luís Felipe. A necessidade de qualidade de vida na terceira idade. Jornal A Hora, Lajeado, 24 mar. 2017.

${ }^{2}$ PISSAIA, Luís Felipe. Aborto afetivo. Jornal A Hora, Lajeado, 04 fev. 2017.

${ }^{3}$ PISSAIA, Luís Felipe. Novos velhos: o envelhecimento no século XXI. Jornal A Hora, Lajeado, 20 fev. 2016.

${ }^{4}$ Filme Holocausto Brasileiro. Disponível em: <https://www.youtube.com/watch?v=CVMGZqV2cP4>. Acesso em 20 jun 2017.
} 
em conjunto com os conteúdos, instigando a realização de reflexões e verbalizações das mesmas em discussão do grupo.

Neste sentido, como comentado anteriormente cada módulo possui três avaliações, sendo que o processo guiado pela problematização compreendeu a última e ocorreu por meio da produção de um texto reflexivo sobre os artigos e vídeo trabalhados em aula. Cabe ressaltar que a metodologia da problematização foi utilizada como uma das três avaliações, no entanto, ela foi trabalhada na totalidade das aulas do módulo, pois se acreditou ser pertinente explorar a tendência junto a todo o conteúdo abordado.

Para a realização do processo avaliativo, além das discussões realizadas em sala de aula foi solicitado aos estudantes a entrega de um texto reflexivo sobre os artigos e vídeo trabalhados em aula, onde pudessem expressar as modificações que a problematização trouxe para sua prática. A orientação é que os textos fossem produzidos fora do momento de aula, escritos a próprio punho em no máximo duas páginas e entregues na aula subsequente. A coleta de dados ocorreu por meio da análise destes textos produzidos e do diário do professor, onde se realizou o registro de alguns momentos das discussões realizadas.

Para a realização do processo avaliativo, além das discussões realizadas em sala de aula que renderam as reflexões que permeiam este estudo, foi solicitada aos estudantes a entrega de um texto reflexivo sobre os artigos e vídeo trabalhados em aula, onde pudessem expressar as modificações que a problematização trouxe para sua prática. Alguns excertos dos textos, bem como falas dos estudantes foram transcritos nesta categoria, utilizando-se como codinomes a letra "E" em sua apresentação maiúscula acompanhada de números arábicos consecutivos.

RESULTADOS E DISCUSSÃO 
Nesta etapa do estudo serão abordados os resultados obtidos a partir do objetivo previamente delimitado, juntamente com as discussões pertinentes sobre os achados tendo como base autores que fundamentam a área de avaliação das aprendizagens em saúde. A seguir serão apresentadas as categorias temáticas, a saber, a primeira, intitulada "Os estudantes e a avaliação do módulo", onde se demonstra os medos e anseios dos próprios estudantes participantes da pesquisa. E, a segunda "O professor no contexto do processo avaliativo", denota a dificuldade em abstrair-se de um modelo avaliativo tradicional e inflexível.

\section{Os estudantes e a avaliação do módulo}

Logo após ser explanada a atividade de realização de textos reflexivos, E2 comenta: "Isso é muito difícil, pensar sobre aquilo que faríamos", ainda em consonância E4, complementa: "Sempre nos oferecem tudo pronto, às vezes nem pensamos naquilo que fizemos na prática, e quando voltamos a pensar a gente vê a diferença", concordando com as falas, E1 afirma: "Ver o vídeo, e ler os texto é muito bom, consegui ver o outro lado, sobretudo com repensar aquilo que faço todos os dias".

Algumas dificuldades na compreensão da atividade foram verificadas, tendo-se, por exemplo, a afirmação de E5: "Nunca fiz isso, pensar sobre aquilo que faço a partir do conteúdo, principalmente escrever", ainda E3, comenta: "Tenho vergonha, porque certamente faço muitas coisas erradas e com as atividades consegui perceber que temos outras formas de fazer". Ainda sobre as dificuldades, E3 comenta: "Não sei escrever bem, nunca cobraram isso de mim, vou tentar fazer o melhor, mas é difícil tirar da cabeça algo assim". Neste sentido, Fernandes (2014) nos fomenta a necessidade de uma prática embasada na reflexão crítica do saber fazer e neste sentido imbrica o conhecimento científico com o empírico a fim de instrumentalizar estes momentos.

As atividades foram realizadas em casa e entregues na aula posterior em um documento escrito a próprio punho, não foram definidos os números de páginas do texto, no entanto, verificou-se que quatro alunas escreveram uma página, enquanto uma escreveu duas páginas. Algumas assertivas que refletem a ideia central de cada texto foram transcritas na integra abaixo: 
Nunca havia pensado nisso, o professor demonstrou um lado que nem em imaginação poderia lembrar que trabalharíamos, percebi muito a importância da nossa profissão neste espaço, principalmente fazendo diferente, não sendo igual aos outros, que só machucam as pessoas. (E 2)

Fiquei em choque quando assisti ao filme e depois o segundo texto do aborto, pois mostrou muita coisa que às vezes bloqueio para fingir que não existe e ficar longe. Mas ainda assim gostei porque me fez pensar o que estou fazendo aqui, onde vou trabalhar e com quem. (E 3)

Assisti tudo e depois fui para casa e não conseguia dormir, pois na discussão que fizemos com os colegas surgiram tantas situações quase que parecidas que fiquei pensando em como fazer diferente. Ainda reli o texto no outro dia de manhã, eles deram uma direção do que fazer tipo assim eles falam aquilo que todos escondem. (E 1)

Respondendo a pergunta do professor, os textos mexeram muito, fui conversando com a minha colega até em casa, continuamos no ônibus, contei para a minha mãe e ela quase não acreditou em tudo o que falei, não temos parentes muito idosos então sei lá, parece que não existe. (E 4)

Gostei das atividades desse módulo de anatomia, parece que saímos só da matéria chata e consegui ver como se usa aquilo, sempre vou lembrar daquilo que conversamos em circulo, foi muito importante e vai me ajudar depois de formado a pensar no certo antes de fazer errado. (E 5)

Percebeu-se que a metodologia da problematização ofereceu um momento de reflexão aos estudantes, E2, por exemplo, expõe em seu trecho: "Nunca havia pensado nisso [...]", já E3 comenta no texto: "Fiquei em choque quando assisti ao filme [...]". As reflexões foram profundas e duradouras, pois se verificou no trecho de E4 uma preocupação em compartilhar seu ponto de vista e observar as ligações com os demais, como se observa a seguir: "[...] fui conversando com a minha colega até em casa, continuamos no ônibus, contei para a minha mãe e ela quase não acreditou em tudo o que falei [...]".

As reflexões sobre a realização de suas práticas também estiveram presentes, E3, por exemplo, defende: "[...] gostei porque me fez pensar o que estou fazendo aqui, onde vou trabalhar e com quem", o aprofundamento das questões partiu também da própria necessidade de sentir-se qualificado, conforme E1 escreve: “Ainda reli o texto no outro dia de manhã, eles deram uma direção do que fazer tipo assim eles falam aquilo que todos escondem". Ainda E5 complementa sobre a importância destes momentos de problematização para a prática futura, no seguinte trecho: "[...] conversamos em circulo, foi muito importante e vai me ajudar depois de formado a pensar no certo antes de fazer errado". 
Os estudantes demonstraram entusiasmo em realizar a problematização no decorrer das aulas, citando ainda alguns dos textos e filme como base para as próprias reflexões e após com o grupo, conforme E5 expos em seu texto: "Gostei das atividades desse módulo de anatomia, parece que saímos só da matéria chata e consegui ver como se usa aquilo, sempre vou lembrar daquilo que conversamos em circulo [...]" A desmistificação que emanou e aflorou em sala de aula compara-se com a que Freire (1979, p. 66) cita desacomodar, no trecho abaixo:

\begin{abstract}
Cada vez mais sentíamos, de um lado, a necessidade de uma educação que não descuidasse da vocação ontológica do homem, a de ser sujeito, e, por outro, de não descuidar das condições peculiares de nossa sociedade em transição, intensamente mutável e contraditória. Educação que tratasse de ajudar o homem brasileiro em sua emersão e o inserisse criticamente no seu processo histórico. Educação que por isso mesmo libertasse pela conscientização.
\end{abstract}

Tirar a aquietação, e deste modo oferecer algo a mais, disponibilizar-se ao novo abrindo caminho para aquilo que se prostra a nossa frente, pode ser verificado no trecho de E2, a seguir: "[...] percebi muito a importância da nossa profissão neste espaço, principalmente fazendo diferente, não sendo igual aos outros, que só machucam as pessoas". Conforme Fernandes (2014), a reflexão nos tira da mesmice, desgrenha situações preconceituosas e informa aquilo que antes permanecia desconhecido. Neste sentido a subjetividade é fomentada por meio de momentos onde a liberdade de expressão impere no conjunto humano. Hartz (2017), colabora instruindo uma análise sem preconceitos, onde se conversa e discute sobre um objeto ou situação, fortalecendo as consonâncias de compreensão do meio.

\title{
O professor no contexto do processo avaliativo
}

A categoria faz analogia às três avaliações de cada módulo do curso, que por mais que os métodos fossem plausivelmente libertos, a denominação nota permanece no obscuro preconceito anteriormente discutido. Agora é o momento de indulgência, de mostrar o que de fato tornou-se efetivo perante os objetivos da avaliação, as percepções do próprio professor quanto aos resultados.

De fato, o medo de errar, de não estar sendo efetivo e, sobretudo, de devolver o estudante à sociedade sem capacitação permearam todo o processo de construção do processo avaliativo. A avaliação por meio da metodologia da problematização exige a 
capacidade de despir-se de modelos pragmáticos que permeiam a jornada acadêmica. Neste sentido, um processo interliga várias faces dentro de um mesmo espaço, possibilitando a sua condensação e sintetização, atraindo ainda um fluxo contínuo de informação que se renovam.

A mudança reflexiva faz parte do ser humano, sob o âmbito do professor ela torna-se necessária devido ao seu compromisso com a sociedade na formação dos profissionais, conforme refere Freire (1979, p. 16), no seguinte trecho:

\begin{abstract}
Se a possibilidade de reflexão sobre si, sobre o seu estar no mundo, associada indissoluvelmente à sua ação sobre o mundo, não existe no ser, seu estar no mundo se reduz a um não poder transpor os limites que lhe são impostos pelo próprio mundo, do que resulta que este ser não é capaz de compromisso. É um ser imerso no mundo, no seu estar, adaptado a ele e sem ter dele consciência. Sua imersão na realidade, da qual não se pode sair, nem "distanciar-se" para admirá-la e, assim, transformá-la, faz dele um ser "fora" do tempo ou "sob" o tempo ou, ainda, num tempo que não é seu.
\end{abstract}

Percebeu-se que a avaliação perdeu o medo e a preconcepção de punição que fora observado no módulo anterior. Na verdade os estudantes não se deram por conta do espaço avaliativo, pois a problematização evocada infundiu uma vivacidade em suas compreensões e sentimentos oriundos de cada reflexão. Após a entrega dos textos, E2 comenta: “Sério que isso é prova, que ótimo, consegui aprender mais que aquela de marcar as alternativas, aqui eu tive que pensar muito", em consonância com a colega, E5 fala: "Achei muito legal mostrar o material, principalmente os vídeos pra nós pensarmos sobre o que fizemos em nosso trabalho" e E3 finaliza com seu ponto de vista: "Certamente, conversar todos juntos nos faz rever algumas coisas e fazer diferente". Fernandes (2014) enfatiza a necessidade de instrumentalizar momentos avaliativos em saúde por meio de metodologias diferenciadas e que confiram aporte para o estudante compreender os inicios, meios e fins do processo.

Ainda mais importante do que dialogar, os estudantes se sentiram parte do processo, integrantes de um mesmo meio de construção do saber, onde as aprendizagens individuais tornaram-se coletivas e exemplificadas com situações problema vivenciadas cotidianamente. Alguns questionamentos foram verificados sobre a avaliação, como o de E2: “Como assim, essa prova vai ser só escrita sobre aquilo que a gente discutiu?", e ainda sobre este 
assunto, E4 fala: "Não escrevi tão bem, achei que tivesse outra prova para fazer nessa aula, na próxima vou fazer duas folhas".

Neste contexto, os autores Sordi e Ludke (2009) evocam o papel do estudante no processo avaliativo, compartilhando a responsabilidade perante o professor e a sociedade que dialoga diretamente com a necessidade de profissionais reflexivos, capazes de deter o conhecimento por vontade própria. Ainda assim, Hartz (2017), traz que no espaço de discussão, os indivíduos são capazes de trazer a tona situações pontuais vivenciadas e que agregam aos demais presentes, instruindo de novas possibilidades em diferentes patamares da avaliação.

Pactua-se que a avaliação foi efetiva a partir dos conteúdos propostos, pois de modo subjetivo tornou-se capaz de trazer a tona os conhecimentos dos estudantes, interrelacionando os conteúdos abordados durante o módulo com as próprias compreensões do meio. Tal afirmativa pode ser verificada nos comentários de E1, que infere: “A problematização que o professor fez foi muito boa, consegui repensar naquilo que faço", ainda sob o mesmo limiar, E5 refere: "Consegui aprender muito, entendi o conteúdo conversando com os colegas durante o grupo, todos se ajudando com o professor", e E2 finaliza interpelando: "Gostaria que fosse feito isso em todas as aulas, porque nos faz pensar sobre as coisas que aprendemos". Quando o estudante participa do processo avaliativo, ele torna-se o sujeito das ações, segundo Fernandes (2014), o empoderamento gerado por esta prática resulta no dinamismo do processo de ensino e aprendizagem na sala de aula.

Infere-se ainda o exercício da tomada de decisão, que flexibilizou as discussões e potencializou a aprendizagem baseada no uso do conhecimento aprendido, instrumentalizando a conversão da subjetividade da avaliação em notas exigidas no currículo. Conforme verificado na fala de E3: "Tudo aquilo que já sabia antes acabou por ajudar no conteúdo, acrescentar conhecimento" e E4 ainda complementa: "Agora sei o que fazer, no que mexer, porque tive que pensar sobre isso e trocar ideias com as colegas".

A subjetividade integra o quadro avaliativo, pois independente da perspectiva em que se observem os indivíduos são únicos e conforme Fernandes (2014), o contexto geográfico e político que o estudante encontra-se inserido influenciam substancialmente nas próprias decisões, estando capacitado a diagnosticar as possibilidades, absorvendo-as e optando pelas certeiras. Sob este patamar, Ribeiro, Dovigo e Silva (2016), perfazem sobre a 
potencialização de algo, principalmente na área da avaliação do ensino permeiam a construção de um cenário diferenciado, onde as condutas individuais misturam-se com o coletivo, transformando em sofisticadas conjunturas.

\section{CONSIDERAÇÕES FINAIS}

Com a realização deste estudo vivenciou-se as dificuldades em aderir e estar disponível às mudanças no contexto da sala de aula, pois a pressão externa que compõe as exigências de formação, acompanhadas pelos modelos curriculares tradicionais que acabam por influenciar na forma de aplicação de novos modelos avaliativos. Ainda assim tornou-se recompensador estruturar a base do que viria a ser um processo avaliativo eficaz e condizente com os objetivos do curso.

Verificou-se que os estudantes ainda demonstram preconceito sobre a avaliação, pois se demarcam sob a ótica utilitarista e pragmática deste modelo, o qual não favorece a miscigenação de ideias e transformação de comportamentos. Percebeu-se nas falas dos estudantes que as discussões surtiram efeitos eficazes, sobretudo utilizando-se de material de apoio que suscitaram as problematizações iniciais ao processo avaliativo, verificando-se que a metodologia empregada é capaz de instrumentalizar novas perspectivas sobre o assunto.

Presenciaram-se dificuldades em desenvolver o texto, no entanto os resultados surpreenderam e renderam frutos no que diz respeito à aprendizagem dos estudantes, ainda que de modo subjetivo partiu-se de um ponto seguro para compatibilizar as notas exigidas. Observa-se uma diversidade de manifestações do conhecimento aprendido em formato de decisões a serem geridas e tomadas frente ao problema tornou-se o principal fator a ser observado.

Considera-se que o estudo torna-se limitado por utilizar o método de problematização como processo avaliativo de uma única turma de estudantes, não demonstrando as variáveis que podem influenciar em seus resultados, como por exemplo, a idade e nível de instrução. Com base nesta preocupação novos estudos estão em andamento, 
bem como discussões com a finalidade de tornar os métodos avaliativos mais condizentes com a realidade dos estudantes.

\section{REFERÊNCIAS}

ALVES, R. C.; FARIA, M. L. C.; COSTA, F. M. Avaliação dos conhecimentos dos alunos sobre a espécie invasora Achatina fulica (Pulmonata, Achatinidae) em uma escola de ensino fundamental de Colorado do Oeste, Rondônia, Brasil. Gaia Scientia, v. 11, n. 1, 2017.

BATISTA, V. M. D. et al. Avaliação do conhecimento e atitudes dos profissionais de saúde de um hospital de ensino sobre proteção radiológica. 2017.

CARNEIRO, V. F. et al. Avaliação da aprendizagem: concepções e olhares de docentes do curso de odontologia. Revista Ibero-Americana de Estudos em Educação, v. 12, n. esp., p. 900-915, 2017.

CARVALHO, R. M.; MEIRELLES, R. M. S. Ensino de Ciências e Saúde para Idosos: Uma proposta de construção de Cartilha Informativa em Grupos de Convivência. Revista Práxis, v. 1, n. 2, 2017.

COSTA, G. D.; COTTA, R. M. M. Representações sociais de estudantes da saúde sobre o portfólio reflexivo como método de ensino, aprendizagem e avaliação. CIAIQ2016, v. 1, 2016.

COUTINHO, C. V.; DIAS, G. Á. Curta SUS: avaliação sobre um projeto de cinema e educação popular na promoção à Saúde Pública. Revista Brasileira de Pesquisa em Saúde, v. 18, n. 4, p. 46-54, 2017.

CUNHA, M. et al. Atitudes do enfermeiro em contexto de ensino clínico: uma revisão da literatura. MilleniumJournal of Education, Technologies, and Health, n. 38, p. 271-282, 2016.

FERNANDES, D. Avaliações externas e melhoria das aprendizagens dos alunos: questões críticas de uma relação (im)possível. Conferência apresentada no colóquio: Avaliação externa e qualidade das aprendizagens. Conselho Nacional de Educação, 2014.

FREIRE, P. Educação e mudança. 27ª Ed. Paz e Terra. 1979.

GUERIN, C. S. et al. Promovendo educação em saúde no espaço não formal de aprendizagem. Revista Brasileira em Promoção da Saúde, v. 30, n. 1, p. 5-12, 2017.

HARTZ, Z. M. A. Cuidados primários, avaliação e ações intersetoriais em promoção da saúde. Ciência \& Saúde Coletiva, v. 22, n. 3, p. 687-688, 2017.

POLIZELI, L. V. B. et al. Caracterização e impacto dos projetos de pesquisa em saúde encaminhados a um conselho municipal de avaliação em pesquisa. Revista de Enfermagem do Centro-Oeste Mineiro, v. 7, 2017.

RIBEIRO, D. G.; DOVIGO, L. N.; SILVA, S. R. C. Avaliação de um método educativo em saúde bucal aplicado em escolares de ensino público. Arquivos em Odontologia, v. 45, n. 3, 2016.

ROCHA, P. F.; WARMLING, C. M.; TOASSI, R. F. C. Preceptoria como modalidade de ensino na saúde: atuação e características do preceptor cirurgião-dentista da atenção primária. Saberes Plurais: Educação na Saúde, v. 1, n. 1, 2016.

SANTOS, B. É. F. Avaliação discente sobre interação ensino, serviços e comunidade em equipes de saúde integradas ao Programa Mais Médicos em estado da Amazônia. 2016. 
Metodologia de problematização como processo avaliativo em um curso profissionalizante na área da saúde

SORDI, M. R. L.; LUDKE, M. Da avaliação da aprendizagem à avaliação institucional: aprendizagens necessárias. Avaliação, Campinas, Sorocaba, SP, v. 14, n. 2, p. 253-266, 2009.

VELOSO, L.; ABRANTES, P.; CRAVEIRO, D. A avaliação externa de escolas como processo social. Educação, Sociedade \& Culturas, n. 33, p. 69-88, 2011.

XAVIER, D. B. et al. Portfolio Reflexivo Eletrônico: experiência inovadora de sanitaristas na Residência Multiprofissional em Atenção Básica do Hub/UnB. Tempus Actas de Saúde Coletiva, v. 11, n. 1, 2017.

ZIMMERMANN, M. H.; SILVEIRA, R. F. M.; GOMES, R. Z. Formação continuada no ensino de ciência da saúde: avaliação de habilidades e feedback efetivo. Ensino \& Pesquisa, v. 14, n. 02, 2016. 